\title{
Computer Tomography: A Useful Instrument for Failure Analyses
}

\author{
Michael Panzenböck, Marlies Borchert
}

\section{Department of Physical Metallurgy and Materials Testing, Montanuniversität Leoben, Austria}

During his experimental work, C. W. Röntgen discovered 1895 a curious electromagnetic radiation, which he called simply X-rays. He found out that the radiation was able to penetrate solid materials. This way it was possible to give someone the opportunity to "look" inside materials. Nowadays this technique is essential for medical use and materials science. Especially for non destructive testing high resolution computer tomography (CT) was further developed. Typical examples of CT applications in the field of failure analyses are given here.

An electromagnetic valve mounted in water installations failed. Unfortunately, this causes flooding of many floors of a laboratory building. In addition to the damages on the building itself, in many cases the electronic equipment was destroyed too. A check of all installed valves proofed that most of them were leaky. These tests showed no failure of the electronic or magnetic device, which is mounted to the valve (Fig. 1). T herefore investigations had to be carried out to find the circumstances of failing.

The main parts of such valves are depicted in Figs. 1a-1c, whereas Fig.1d shows its cross section. In Fig. 2 a typical two-dimensional X-ray photograph of the valve is shown, which was responsible for the disaster. In this figure only the contours of the valve are dimly visible. But there is no way to have a closer look into the inside in detail. On the contrary CT allows a view of the cross section in steps. One can say it is possible to take "a walk" through the valve. As can be seen from Fig. 3 this technique allows to distinguish between metal parts and components made of plastic. The diaphragm with its special form is clearly visible. Within the red marked region in Fig. 3 a very thin foreign particle can be i dentified. Further investigations showed, that this object can be related to a chromium flitter. Even more, comparison of the cross sections of a new valve (Fig. 4a) and a valve taken from the water installation (Fig. 4b) show clearly differences between the positions of the main orifice. For the new valve the main orifice blocks the flow of fluid and the diaphragm is in close contact with the sealing edge. In contrast to this, the main orifice in the failed valve (Fig. $4 \mathrm{~b}$ ) is not closed. Within the red marked circle a small particle between diaphragm and sealing edge is visible. Further investigations showed that all found particles can be attributed to the tubes of the water installation. These particles origin from cutting the tubes during manufacturing. So the pipework was not cleaned sufficient after installation.

Another example for using CT is presented in the insert of Fig. 5. These small screws (M6) are used for fixing lamps in tunnels. Normally they are made of a high corrosion resistant steel like AISI 316L (X2CrNiMo17-12-2). From a CT cross section (Fig. 5) of the screw near the fracture surface many cracks can be identified. All these cracks are in itiated within the grooves of the thread. Scanning electron microscope (SEM) investigations show clearly (Fig. 6) the presence of stress corrosion cracking (SCC). These conclusions can be drawn due to the presence of many branched cracks (Fig. 5) and the factory roofed structure of the fracture surface. Ch emical investigations reveal that the material of the screw belongs to the family of corrosion resistant steels, but only of the AISI 304 (X5CrNi18-10) quality. On the fracture surface and other regions, high concentrations of chlorides were identified too. 


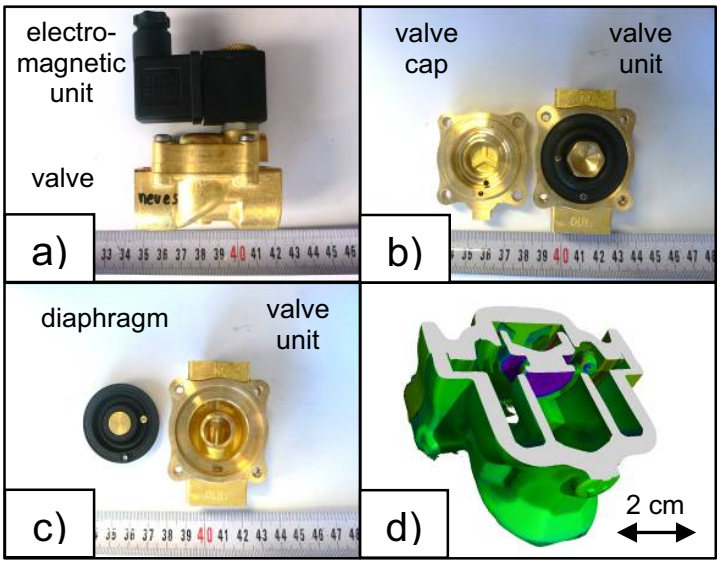

Figure 1. a) Macroscopic overview of an electromagnetic valve; $b, c)$ disassembled valve; d) CT cross section of a valve

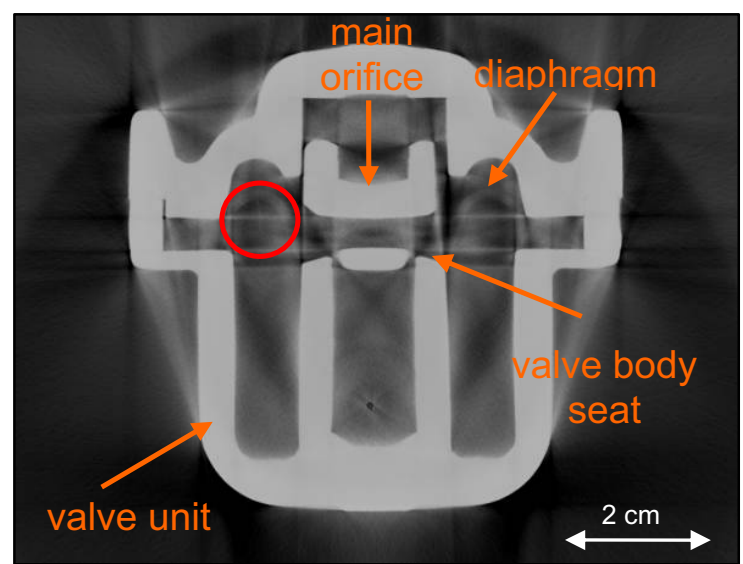

Figure 3. CT of an installed valve. The red circle marks a sm all metallic flitter. The diaphragm is also visible.

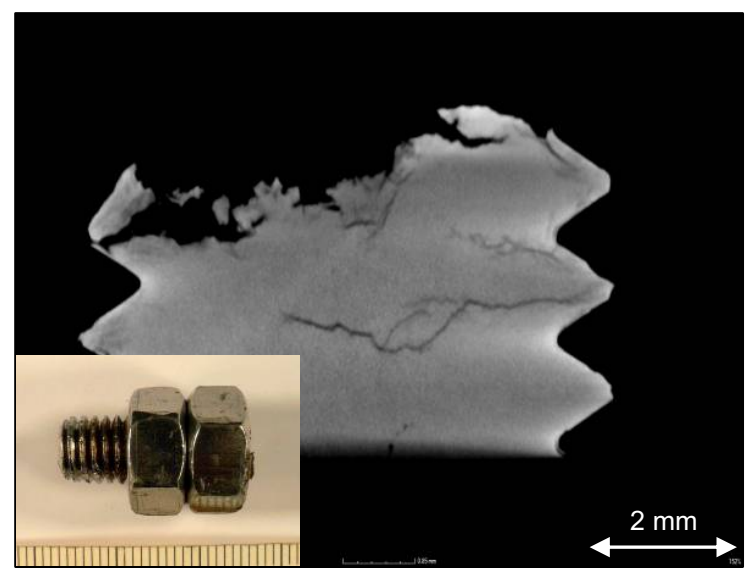

Figure 5. CT of a small part taken from a failed screw (see insert). Many cracks are initiated in the grooves of the thread.

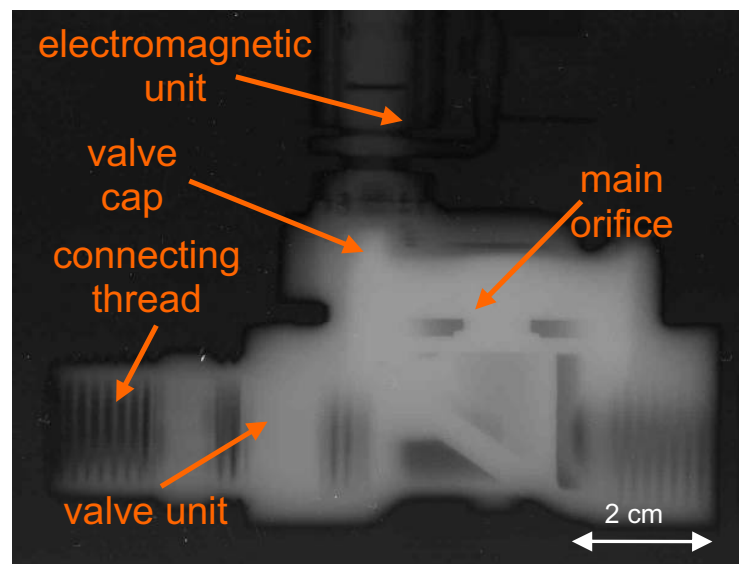

Figure 2. Two dimensional X-ray photograph of an electromagnetic valve. The main parts are marked with arrows.

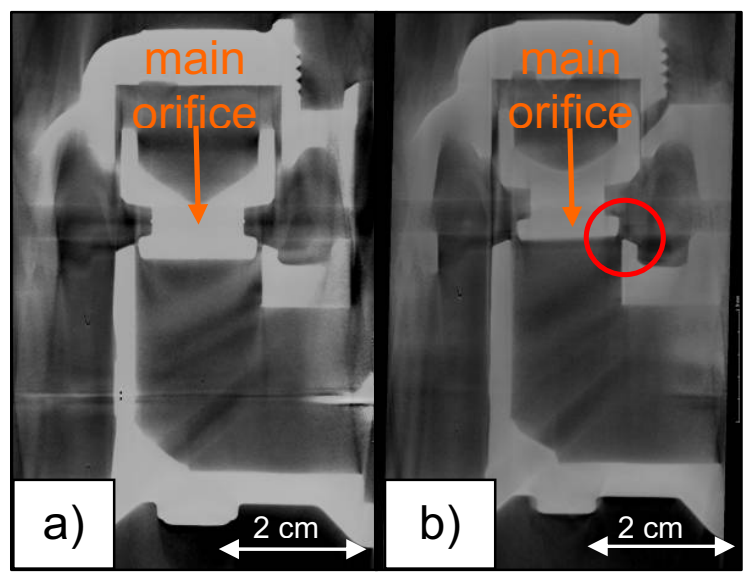

Figure 4. Comparison of two valves: (Fig. 4a) new valve, (Fig. 4b) valve from the installation. Red circle marks a particle.

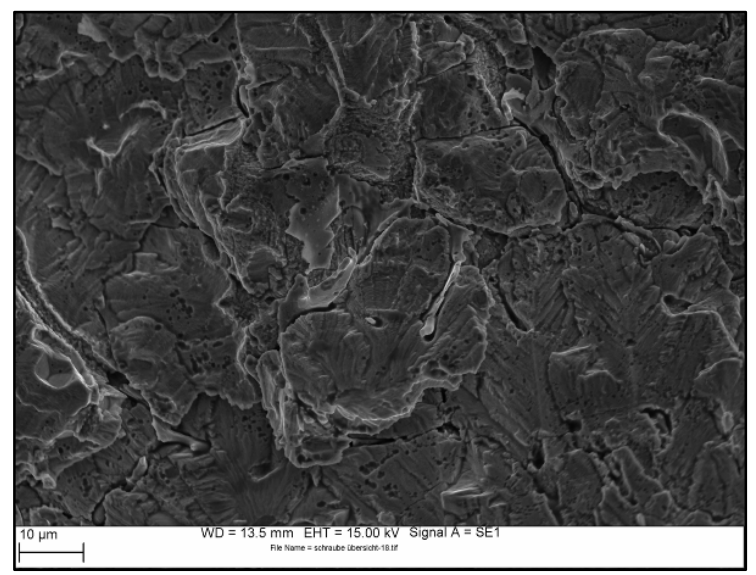

Figure 6. SEM $\mathrm{m}$ icrograph of the fracture surface of the screw (see Fig. 5). Secondary cracks and factory roofs are visible. 